\title{
Steady-State Analysis Of Single Phase IPM Motors By D-Q Harmonic Balance Method
}

Original Scientific Paper

\author{
Asogwa Jude. C. \\ Energy Commission of Nigeria, \\ Abuja, Nigeria \\ jasogwa@yahoo.com

\section{Obe Emeka. S.} \\ University of Nigeria, Nsukka \\ Faculty of Engineering, Department of Electrical \\ Engineering \\ Enugu State, Nigeria \\ simon.obe@unn.edu.ng
}

\author{
Nnadi Damian. B. \\ University of Nigeria, Nsukka \\ Faculty of Engineering, Department of Electrical \\ Engineering \\ Enugu State, Nigeria \\ damian.nnadi@unn.edu.ng \\ Oti Stephen. E.* \\ University of Nigeria, Nsukka \\ Faculty of Engineering, Department of Electrical \\ Engineering \\ Enugu State, Nigeria \\ stephen.oti@unn.edu.ng \\ *Corresponding Author
}

\begin{abstract}
A concise steady-state analysis of a single-phase line-start permanent magnet (SPLSPM) machine is conducted from a developed $d$-q model using the $d$-q harmonic balance technique. The $d$-q model was developed in the rotor reference frame from a phase variable model of the machine. SPLSPM whose performance indices were characterized by high torque ripples has detailed analysis docile mostly in computer simulations quite unlike the three-phase types. The main cause is not far-fetched, it was due to the nonexistence of a precise mathematical model in the d-g rotor frame of the motor due to the unbalanced field winding, the rotor saliency, and the presence of the capacitor in the auxiliary windings. Even after the model has been developed, the simple traditional procedure of setting all time-varying components to zero for steady-state analysis fails because the rotor position dependence on the inductance expressions could not be eliminated. The $d$-q harmonic-balance technique was then applied. The analysis and simulation were carried out using MatLab/Simulink software. An important feature of the harmonic balance technique was that it decoupled all equations to simple sine waveforms in a style that resembled the Fourier series. Results yield torque pulsation, current, and load characteristics in the steady-state.
\end{abstract}

Keywords - Torque, Capacitor, Permanent magnet, Transformation, Transient

\section{INTRODUCTION}

The high-efficiency rating of an interior permanent machine (IPM) among other single-phase motors makes it have the potential of replacing other classes of single-phase machines for both household and industrial applications. In the range of a few hundred watts, single-phase machines were customarily employed in the control, and in small energy drives, robotics and other associated usages which needed meticulous and high-power factor. Even though IPM synchronous motor is comparatively straightforward in building, it is rather very tough in analysis relative to its counterpart, 3 - $\Phi$ machines due to asymmetrical nature of the motor as a result of unevenness in the field winding arrangement, irregular air-gap length, the presence of start and run capacitors. For the mere fact that its per- formance index is characterized by high ripple torque, it tends to complicate further its analysis [1, 2]. In the process of carrying out a closed examination of the steady-state of IPM synchronous motor, it is quite relevant to be able to predict adequately the machine performance characteristics under a wide range of loading conditions [3]. Adequate studies were therefore performed for dynamic analysis. At present, there is not much literature available on this area and aspect of study so that an elaborate comparison would be made. Although [4,5] worked on Interior Permanent Motor, their concern was on other issues away from the $d-q$ harmonic method. For instance [5] was interested in investigating the steady-state and dynamic response of an interior permanent magnet (IPM) synchronous machine drive to a single-phase open-circuit fault. In the past, Miller [6] developed a unified tactic in the analysis 
of single-phase (1-Ф) machines conditioned on Fortescu's symmetrical component method which gave room for the application of intuitive reasoning. In like manner, [7] looked at the deployment of the technique in rotor current evaluation in respect of single-phase synchronous reluctance motor. However, this work attempts to present a detailed analytical model that will adequately predict single-phase machine IPM motor characteristics at a wide range of operating condition.

\section{THE MATERIALS AND METHODOLOGY}

Figure 1 shows the IPM machine made up of main and supplementary windings that were 900 electrical out of phase with each other. The capacitor was connected to auxiliary (supplementary) winding in series, in this way an additional phase was created from the 1- $\Phi$ supply. That connection made it possible for the machine to start directly online. The centrifugal switch as connected was to disconnect the start capacitor as soon as the motor has attained the required speed; the series capacitor ensured that the motor maintains a moderately high running torque, power factor with fewer torque pulsations [8]. By estimating the capacitance value of such capacitor used and applying such values for all the machine loading states, the optimum performance of all such machines is attained at alltimes. For this analysis, the rated value of starting and running capacitor for the motor employed was $50 \mu F$ and $15 \mu F$ respectively. For the transition to synchronism, a précised switching speed be estimated such that the ripples produced at switching be minimal.

\subsection{The Model of the Machine}

Generally, as opined by [9], all single-phase machine transformations in the $d-q$ axis were rotor position-dependent since the field windings were not balanced in the company of capacitor in the supplementary winding and the air gap not constant. The researchers in [10], thought that time-varying constraints cannot be completely removed by any reference frame transformations, however, they derived the $\mathrm{d}$ - $\mathrm{q}$ axis transformation for the capacitor voltage equation of the machine.

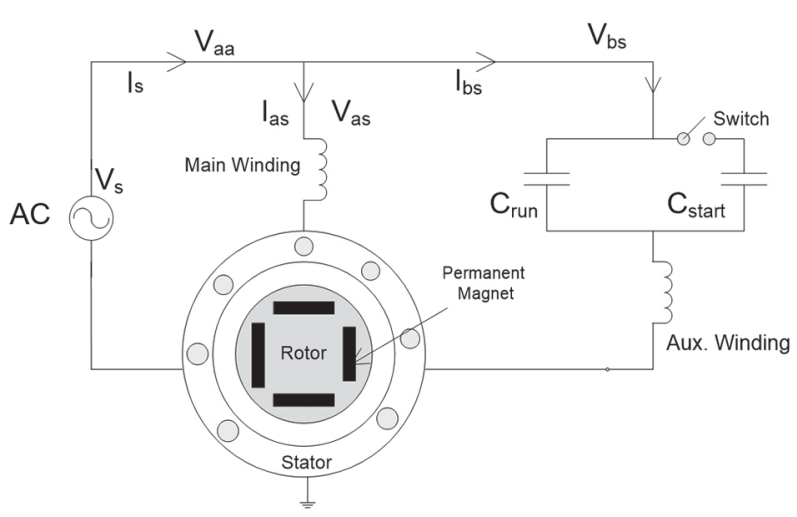

Fig.1. The diagram of the machine field winding and its rotor structure
$V_{q s}=r_{a a} I_{q s}+r_{a b} I_{d s}+\omega_{r} \lambda_{d s}+p \lambda_{q s}+V_{q c}$

$V_{d s}=r_{b b} I_{d s}+r_{a b} I_{q s}-\omega_{r} \lambda_{q s}+p \lambda_{d s}+V_{d c}$

$V_{q r}=r_{q r} I_{q r}+p \lambda_{q r}$

$V_{d r}=r_{d r} I_{d r}+p \lambda_{d r}$

$p V_{q c}=-\omega_{r} V_{d c}+\frac{1}{2 c_{d}}\left(I_{q s}-I_{d s} \sin 2 \theta_{r}-I_{q s} \cos 2 \theta_{r}\right)$

$p V_{d c}=\omega_{r} V_{q c}+\frac{1}{2 C_{d}}\left(I_{d s}-I_{q s} \sin 2 \theta_{r}+I_{d s} \cos 2 \theta_{r}\right)$

where,

$$
\begin{aligned}
& r_{a a}=\frac{1}{2}\left(r_{a s}+r_{b s}\right)+\frac{1}{2}\left(r_{a s}-r_{b s}\right) \cos 2 \theta_{r} \\
& r_{b b}=\frac{1}{2}\left(r_{a s}+r_{b s}\right)-\frac{1}{2}\left(r_{a s}-r_{b s}\right) \cos 2 \theta_{r} \\
& r_{a b}=\frac{1}{2}\left(r_{a s}-r_{b s}\right) \sin 2 \theta_{r}
\end{aligned}
$$

The under-listed equations are the flux linkage equations:

$$
\begin{aligned}
& \lambda_{q s}=L_{l q s} I_{q s}+\left(I_{q s}+I_{q r}\right) L_{m q} \\
& \lambda_{d s}=L_{l d s} I_{d s}+\left(I_{d s}+I_{d r}\right) L_{m d}+\lambda_{m} \\
& \lambda_{q r}=L_{l q r} I_{q r}+\left(I_{q s}+I_{q r}\right) L_{m q} \\
& \lambda_{d r}=L_{l d r} I_{d r}+\left(I_{d s}+I_{d r}\right) L_{m d}+\lambda_{m}
\end{aligned}
$$

\subsection{The d-q Axis Modeling with Rotor Permanent Magnet}

A rotor coil can be used to model a permanent magnet using a dc excitation current $I_{r m}$, such that $I_{r m}=E_{r o} /$ $w_{r} L_{m d^{\prime}}$ where $E_{r o}$, is the excitation voltage due to magnet in the rotor since the product of magnetic flux linkage and the machine rotor speed, $\omega_{r} \lambda_{m}$ have the dimension of the excitation voltage. The permanent magnet gives a constant flux $\lambda_{m^{\prime}}$, where $\lambda_{m}=I_{r m} L_{m d^{\prime}}$. Flux linkage in the field windings of the 1- $\Phi$ machine due to the permanent magnet in the rotor and which rotates in an unbalanced condition is modeled as [11]:

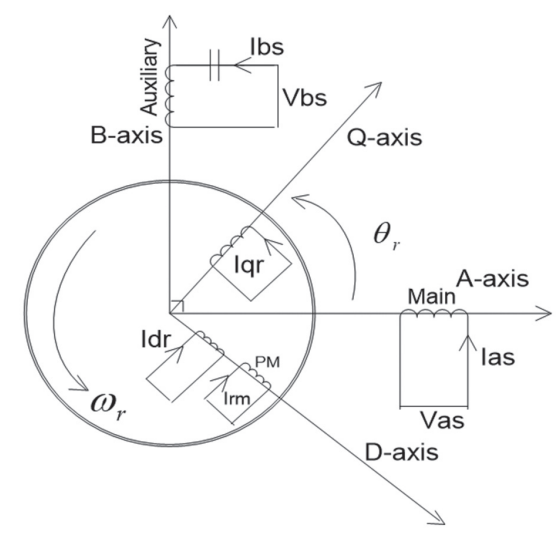

Fig. 2. Modeling of rotating IPM motor in the $q-d$ axis reference frame 
The $q$ - $d$ axis currents of the magnet torque can be derived once the IPM machine operates as a generator and the field winding is bridged, the established torque then became the braking torque produced by the presence of rotor magnets. Because of this, equations (14) and (15) were substituted in the q-d axis voltage equations (1) and (2) while setting the voltages to zero as the machine operates at a constant speed. The $d-q$ axis magnet flux linkage equations, therefore, emerge as stated in equations (16) and (17) below [12].

$$
\begin{aligned}
& \lambda_{q m}=L_{q s} i_{q m} \\
& \lambda_{d m}=L_{d s} i_{d m}+\lambda_{m} \\
& 0=r_{q s} i_{q m}+r_{q d} i_{d m}+\omega_{r} L_{d s} i_{d m}+\omega_{r} \lambda_{m} \\
& 0=r_{d s} i_{d m}+r_{d q} i_{q m}-\omega_{r} L_{q s} i_{q m}
\end{aligned}
$$

Solving equations (16) and (17) simultaneously led to the expressions for $i_{q m}$ and $i_{d m}$ in equations (18) and (19). These were useful for calculating the magnet torque.

$$
\begin{gathered}
i_{q m}=\frac{-\omega_{r} r_{d s} \lambda_{m}}{r_{d s} r_{q s}-\left(r_{q d}+\omega_{r} L_{d s}\right)\left(r_{d q}-\omega_{r} L_{q s}\right)} \\
i_{d m}=\frac{\omega_{r} \lambda_{m}\left(r_{d q}-\omega_{r} L_{q s}\right)}{r_{d s} r_{q s}-\left(r_{q d}+\omega_{r} L_{d s}\right)\left(r_{d q}-\omega_{r} L_{q s}\right)}
\end{gathered}
$$

\subsection{The Machine Dynamic Torque Equations}

At synchronous speed, the electromagnetic torque expression of the single-phase motor with a permanent magnet embedded in the rotor can therefore be expressed into two aspects of cage torque and magnet torque as shown below.

$$
\begin{aligned}
& T_{e m}=T_{c}+T_{m}= \\
& \frac{p}{4}\left(\lambda_{d r} i_{q r}-\lambda_{q r} i_{d r}\right)+\frac{p}{4}\left(\lambda_{d m} i_{q m}-\lambda_{q m} i_{d m}\right) \\
& T_{e m}=\frac{p}{4}\left(\lambda_{d s} I_{q s}-\lambda_{q s} I_{d s}\right) \\
& T_{c}=\frac{p}{4}\left(\lambda_{d r} i_{q r}-\lambda_{q r} i_{d r}\right) \\
& T_{m}=\frac{p}{4}\left(\lambda_{d m} i_{q m}-\lambda_{q m} i_{d m}\right)
\end{aligned}
$$

The above-written equations ( 1 - 9, 10 - 13, and 20 - 25) enable researchers to carry out the fundamental frequency analysis [13] by the use of computer simulations of the machine to obtain the starting transients and steady-state waveforms. The cage and magnet torque of the machine during its asynchronous operation is also deduced in equation (20). The mechanical equations of such a machine (relating the rotor speed with the established electromagnetic torque were described by equations (24) and (25).

$$
\begin{aligned}
& J\left(\frac{2}{p}\right) p \omega_{r}=T_{e m}-T_{L} \\
& \theta_{r}=\frac{1}{p} \int_{0}^{t} \omega_{r} d t
\end{aligned}
$$

\section{APPLICATION OF HARMONIC BALANCE TECHNIQUES TO IPM MACHINE ANALYSIS}

Since the stator winding is not well-adjusted and the air gap is not constant, considering the rotor saliency and the high torque ripples that characterize the performance indices of IPM machines, it has been noted earlier that the time-varying constraints of the motor cannot be removed completely by any reference frame transformation $[3,6]$. It is also unequivocally tough to obtain the numerous current, flux linkage, and torque make-ups and their various sizes (the reason being that they were hooked on to the machine constraints and the capacitor values) without the application of phasor analysis. Those considerations as illustrated informed our decisions to develop an analytical model that will be able to address the presence of the third harmonic currents in the stator windings as a result of the asymmetrical nature of singlephase machines $[13,11]$. If phasor analysis was applied to the time fluctuating differential equation, the harmonic balance automatically decouples the state variables (which was assumed to be indiscriminately periodic) into a mixture of a periodic sinusoid in a style comparable to the Fourier series. As a result of this interactions formed simple time-invariant nonlinear simultaneous equations. Then, the solution of the nonlinear system been created by comparing the matching coefficients of the sinusoid. Let's assume that the machine started at zero voltage angle and the main and supplementary windings were $\pi / 2$ electrical radians out of phase; suppose the phase voltages across the main and auxiliary windings [14] were as shown:

$$
\begin{aligned}
& v_{a s}=V_{a} \cos \left(\theta_{e}+\delta\right) \\
& v_{a s}=V_{a} \cos \left(\theta_{e}+\delta\right)
\end{aligned}
$$

where $V_{a}=V_{b}=V, \theta_{e}=\omega_{e} t$ and ' $\delta$ ' is the voltage load angle. Therefore, the transformation used for an all-state variable in a rotor reference frame is:

$\left[\begin{array}{l}F_{q} \\ F_{d}\end{array}\right]=\left[\begin{array}{cc}\cos \left(\theta_{r}+\varepsilon\right) & \sin \left(\theta_{r}+\varepsilon\right) \\ \sin \left(\theta_{r}+\varepsilon\right) & -\cos \left(\theta_{r}+\varepsilon\right)\end{array}\right]\left[\begin{array}{l}F_{a} \\ F_{b}\end{array}\right]$

Where ' $F$ ' designates current, voltage, or flux linkage in their reference frames. $\theta_{r}=\omega_{r} t$ and ' $\varepsilon$ ' is the original rotor angular spot. Replacing the current, voltage, or flux linkage equations in their corresponding $\mathrm{d}$-q rotor reference frame results in the following real complex phasor expressions with their respective coefficients as in the equations below $[13,11]$ :

$$
\begin{aligned}
& F_{q}=R e\left(F_{q 1} e^{j \theta 1}+F_{q 2} e^{j \theta 2}\right) \\
& F_{d}=\operatorname{Re}\left(F_{d 1} e^{j \theta 1}+F_{d 2} e^{j \theta 2}\right)
\end{aligned}
$$

Where, $\theta_{1}=\theta_{e}+\theta_{r}=\left(\omega_{e}+\omega_{r}\right) t$ and $\theta_{2}=\theta_{e}-\theta_{r}=\left(\omega_{e}-\omega_{r}\right) t$ 
From equations (29) and (30) the d-q voltage equations can be deduced as in equations (31) and (32).

$V_{q s}=\operatorname{Re}\left[V_{q s 1} e^{j \theta_{1}}+V_{q s 2} e^{j \theta_{2}}\right]$

$V_{d s}=\operatorname{Re}\left[V_{d s 1} e^{j \theta_{1}}+V_{d s 2} e^{j \theta_{2}}\right]$

where,

$$
\begin{aligned}
& V_{q s 1}=\frac{1}{2}\left(V_{a}-j V_{b}\right) e^{j \gamma 1}, V_{q s 2}=\frac{1}{2}\left(V_{a}+j V_{b}\right) e^{j \gamma 2} \\
& V_{d s 1}=j V_{q s 1}, V_{d s 2}=-j V_{q s 2}
\end{aligned}
$$

where,

$$
\gamma_{1}=\varepsilon+\delta_{0}, \gamma_{2}=\varepsilon-\delta_{0}
$$

Following the same procedure, other state variables (current and flux linkages) are also decoupled and deduced as the current and voltage expressions. At unchanging conditions, i.e. $\omega_{e}=\omega_{r}$ and then equating to zero the derivatives of the entire new state variables, equations (1-9, 10-13, 31-34) generate the following coefficient matrix as expressed in equation (36) and the machine torque model, while the solution of equations(1-9, 10-13, and 20 - 25) using MATLAB/SIMULINK, yield the machine transient and dynamic conduct of the motor.

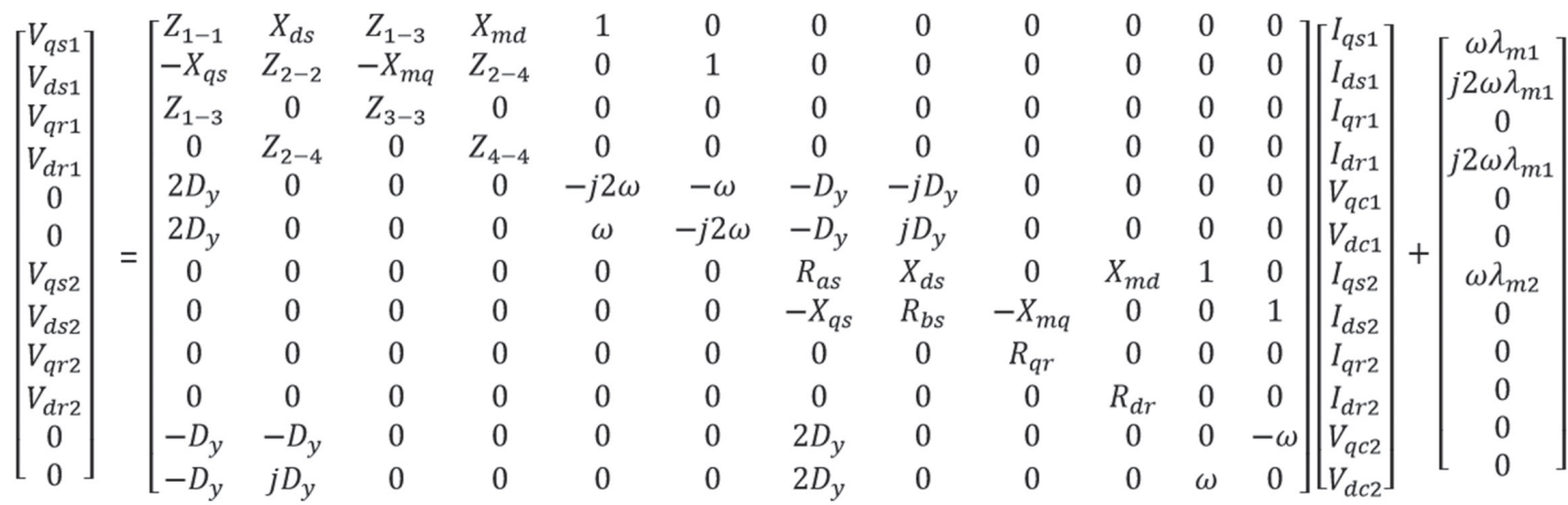

In the equation (36) above,

$D_{y}=\frac{1}{(4 C)^{\prime}} Z_{1-1}=r_{a a}+j 2 X_{q s}, Z_{2-4}=j 2 X_{m d}$,

$Z_{1-3}=j 2 X_{m q}$

$Z_{2-2}=r_{b b}+j 2 X_{d s}, Z_{3-3}=r_{q r}+j 2 X_{q r}, Z_{4-4}$

$=r_{d r}+j 2 X_{d r}$

\subsection{Harmonic Balance Torque Expression}

Applying phasor analysis to the electromagnetic torque equation (21) in a decoupled arrangement by replacing equation (10 - 13) in equations $(1-9)$ also in decoupled form and other physical variables as expressed in equation (31) and (32) and solving algebraically, the harmonic balance torque equations expression in the parts would therefore be derived as illustrated below[14, 15].

$$
=\frac{p}{4} \operatorname{Re}\left[\begin{array}{c}
{\left[\left(L_{m d 1} I_{q s 1}\left(I_{d r 1}+I_{d s 1}\right)-L_{m q 1} I_{d s 1}\left(\left(I_{q r 1}+I_{q s 1}\right)\right]\right.\right.} \\
{\left[\left(L_{m d 2} I_{q s 2}\left(I_{d r 2}+I_{d s 2}\right)-L_{m q 2} I_{d s 2}\left(\left(I_{q r 2}-I_{q s 2}\right)\right]\right.\right.} \\
{\left[\left(L_{m d 1} I_{q s 2}\left(I_{d r 1}+I_{d s 1}\right)+L_{m d 2} I_{q s 1}\left(\left(I_{q r 2}-I_{q s 2}\right)\right]\right.\right.} \\
+\left(\lambda_{m 1} I_{q s 1} e^{j 2 \theta_{1}}\right)+\left(\lambda_{m 2} I_{q s 2} e^{j 2 \theta_{2}}\right)+ \\
\left(\lambda_{m 1} I_{q s 2}+\lambda_{m 2} I_{q s 1}\right) e^{j\left(\theta_{1}+\theta_{2}\right)}
\end{array}\right.
$$

At synchronous speed, $\omega_{r}=\omega_{e}=\frac{d \theta}{d t}, \theta_{1}=\theta_{r}+\theta_{e}$, also $\theta_{2}=\theta_{r}-\theta_{e}$

Therefore,

$$
\begin{aligned}
& T_{e m}=\frac{p}{4} \operatorname{Re}\left[\begin{array}{c}
T_{1} e^{j 4 \theta}+T_{2}+T_{3} e^{j 2 \theta} \\
+T_{4} e^{j 4 \theta}+T_{5}+T_{6} e^{j 2 \theta}
\end{array}\right] \\
& \mathrm{T}_{1 \mathrm{R}}=\frac{\mathrm{p}}{4} \operatorname{Re}\left[\begin{array}{c}
\left(\mathrm{L}_{\mathrm{md} 1} \mathrm{I}_{\mathrm{qs} 1}\left(\mathrm{I}_{\mathrm{dr} 1}+\mathrm{I}_{\mathrm{ds} 1}\right)\right. \\
-\mathrm{L}_{\mathrm{mq} 1} \mathrm{I}_{\mathrm{ds} 1}\left(\left(\mathrm{I}_{\mathrm{qr} 1}+\mathrm{I}_{\mathrm{qs} 1}\right)\right.
\end{array}\right] \mathrm{e}^{\mathrm{j} 2 \theta_{1}}
\end{aligned}
$$

$T_{2}=\frac{p}{4} \operatorname{Re}\left[\begin{array}{c}\left(L_{m d 2} I_{q s 2}\left(I_{d r 2}+I_{d s 2}\right)-\right. \\ L_{m q 2} I_{d s 2}\left(\left(I_{q r 2}-I_{q s 2}\right)\right.\end{array}\right]$

$$
T_{3 S}=\frac{p}{4} \operatorname{Re}\left[\begin{array}{c}
\left(L_{m d 1} I_{q s 2}\left(I_{d r 1}+I_{d s 1}\right)\right. \\
+L_{m d 2} I_{q s 1}\left(\left(I_{q r 2}-I_{q s 2}\right)\right.
\end{array}\right] e^{j\left(\theta_{1}+\theta_{2}\right)}
$$

$T_{4}=\frac{p}{4} \operatorname{Re} \lambda_{m 1} I_{q s 1} e^{j 2 \theta_{1}}$

$T_{5}=\frac{P}{4} R e \lambda_{m 2} I_{q s 2}$

$T_{6}=\frac{p}{4} \operatorname{Re}\left(\lambda_{m 1} I_{q s 2}+\lambda_{m 2} I_{q s 1}\right) e^{j\left(\theta_{1}+\theta_{2}\right)}$

$T_{A V}=T_{2}+T_{5}=\frac{p}{4} R e\left[\begin{array}{c}\left(L_{m d 2} I_{q s 2}\left(I_{d r 2}+I_{d s 2}\right)\right. \\ -L_{m q 2} I_{d s 2}\left(\left(I_{q r 2}-I_{q s 2}\right)+\lambda_{m 2} I_{q s 2}\right.\end{array}\right]$ 


\section{RESULTS}

Fractional (0.5hp) horsepower IPM motor each for $230 \mathrm{~V}, 60 \mathrm{~Hz}$, 8-pole, capacitor start, capacitor run IPM motor 1- $\Phi$ was employed for the research. The pertinent design data in Table 1, as well as the dynamic performance and synchronous operations of the machine, are therefore as presented in [16].

Table 1: The machine parameters for single phase 0.5 hp IPM Motor [16].

\begin{tabular}{|c|c|c|c|}
\hline s/no & Description & Symbol & Value \\
\hline 1 & Stator main winding resistance & ras & $27.7 \Omega$ \\
\hline 2 & Stator auxiliary winding resistance & rbs & $27.7 \Omega$ \\
\hline 3 & Stator $\mathrm{d}$-axis leakage reactance & Llqs & $67 \mathrm{~m} \Omega$ \\
\hline 4 & Stator q-axis leakage reactance & Llds & $67 \mathrm{~m} \Omega$ \\
\hline 5 & Stator d-axis reactance & Lds & $287 \mathrm{~m} \Omega$ \\
\hline 6 & Stator q-axis reactance & Lqs & $511 \mathrm{~m} \Omega$ \\
\hline 7 & Rotor d-axis resistance & rdr & $11 \Omega$ \\
\hline 8 & Rotor q-axis resistance & rqr & $25.8 \Omega$ \\
\hline 9 & Rotor d-axis leakage reactance & Lldr & $178 \mathrm{~m} \Omega$ \\
\hline 10 & Rotor q-axis leakage reactance & Llqr & $179 \mathrm{~m} \Omega$ \\
\hline 11 & Magnetizing d-axis reactance & Lmd & $220 \mathrm{~m} \Omega$ \\
\hline 12 & Magnetizing q-axis reactance & Lmq & $441 \mathrm{~m} \Omega$ \\
\hline 13 & Rotor damper d-axis reactance & Ldr & $378 \mathrm{~m} \Omega$ \\
\hline 14 & Rotor damper q-axis reactance & Lqr & $622 \mathrm{~m} \Omega$ \\
\hline 15 & Rotor moment of inertia & J & $0.0023 \mathrm{Kgm}^{2}$ \\
\hline 16 & Magnetic flux linkage & $\lambda m$ & 0.4 Wb.turn \\
\hline 17 & Starting Capacitor & Cs & $50 \mu \mathrm{F}$ \\
\hline 18 & Running Capacitor & $\mathrm{Cr}$ & $15 \mu \mathrm{F}$ \\
\hline
\end{tabular}

\subsection{The Motor Speed}

Figure 3 showed the dynamic buildup speed from the initial value to synchronous speed for the single-phase IPM motor. The starting of the IPM motor was much more difficult due to the magnetic braking torque and backward moving negative torque. The run-up speed curves showed substantial oscillatory speed response from about 50 radians/sec to $340 \mathrm{radian} / \mathrm{sec}$ as a result of magnet excitation and instantly, it ran up to synchronism after a small overshoot of above 400 radians/sec. It also shows the responses of the motor speed after receiving the step Load of $1 \mathrm{~N}$ at a step time of 1 second. The motor speed responses with time progressively increased in oscillation as the step load increased. The intense oscillatory torque of the IPM motor can be broadly highlighted in Figure 4, toward the mid-portion of torque-speed response where it was puffed up; over few cycles, the motor violently oscillated, it was able to attain synchronism at $375 \mathrm{radian} / \mathrm{sec}$ as displayed.

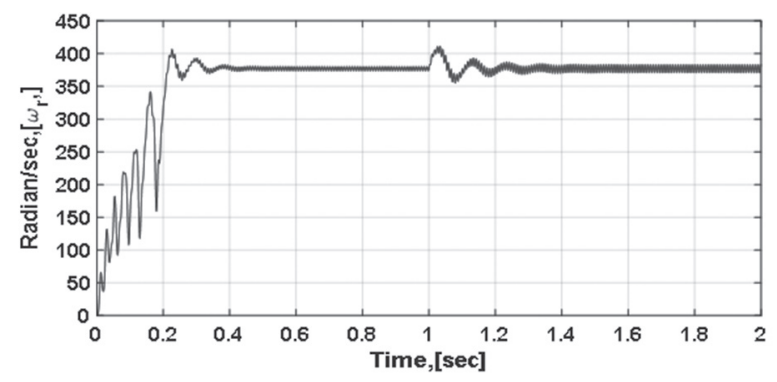

Fig. 3. Speed Versus Time of IPM Motor on $1 \mathrm{~N}$

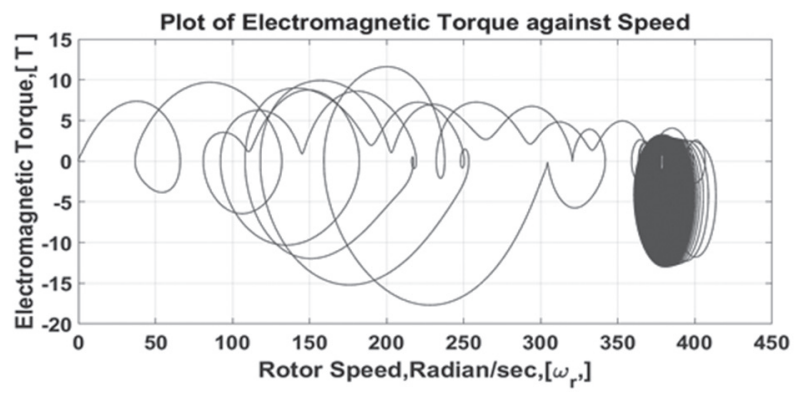

Fig. 4. Torque (Tem) versus Speed for IPM Motor.

\subsection{Motor Currents:}

Figure 5(a) and (b) showcased the core and auxiliary winding of stator currents. In the plots of the stator main and auxiliary windings, it can be easily noted that the magnet braking torque has more impact on the main windings' component than the auxiliary windings since the current waveform displayed amplitude of 2.2 $\mathrm{A}$ and $1.5 \mathrm{~A}$ at a step load of $1 \mathrm{~N}$ respectively. In Figure 6 , the readings of main and auxiliary winding currents on varying loads were displayed. Figure 7 illustrates the plots of electromagnetic, cage, and magnet torque on varying load against load angle which showed readings of $4.7 \mathrm{Nm}, 3.25 \mathrm{Nm}$, and $-7 \mathrm{Nm}$ respectively. Theoretically, the summation of cage torque with the magnet torque resulted in the electromagnetic torque, that is, $T_{e m}=T_{c}+T_{m}$. The bond among the torque plots of Figure 7 slightly did not conform to the theory; the minor difference in the peak torque values of the plots as can be observed accounts for the saturation effect which was not taken into account in the dynamic machine equations.

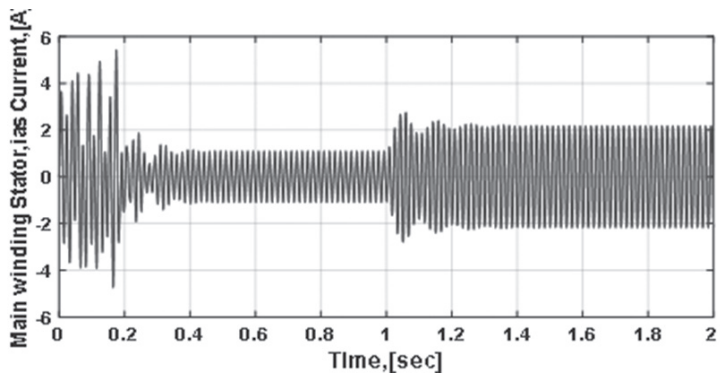

Fig. 5.(a) Current (las) Plots and Time 


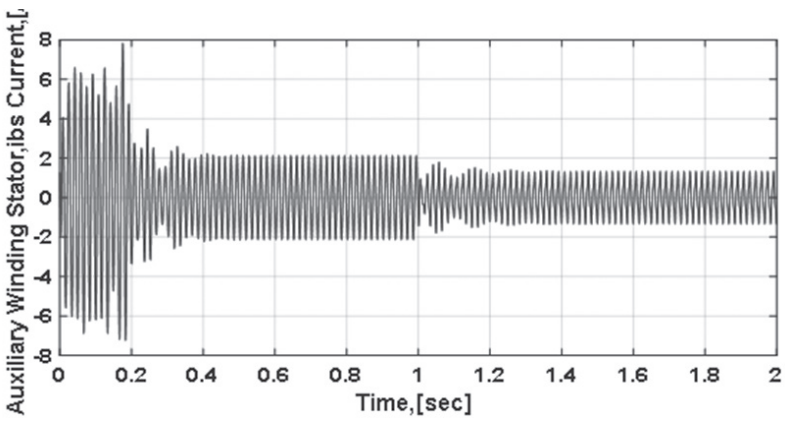

Fig. 5.(b) Current (Ibs) Plots Versus Time

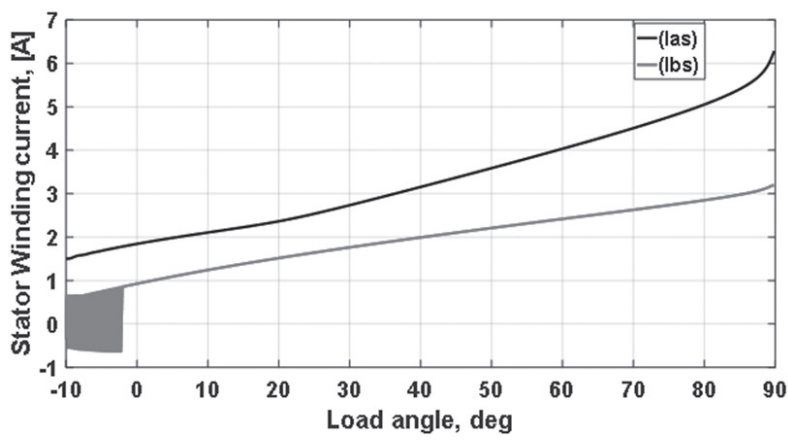

Fig. 6. Main and Aux.Winding plots against Load Angle

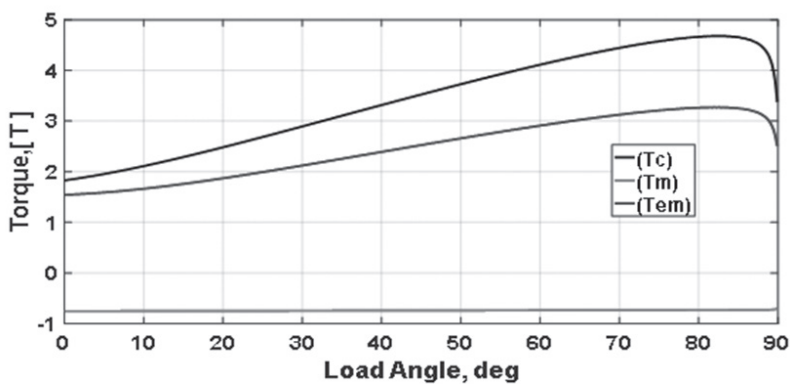

Fig. 7. Torque Plots against Load Angle

\subsection{Harmonic Balance Results}

This paper presented various phasor plots of stator main and auxiliary winding currents in Figure 8, $q$-d stator currents in Figure 9 were plotted with time, the capacitor voltage in Figure 10, and rotor currents as showcased in Figure 11; all these plotted were in response to time. The torque plots were presented in Figures 12, 14, and 16, all were plotted against time at $42^{\circ}$ load angles while Figures 13, 15, and 17 were the responses of torques plots at a varying load angle. The phasor current plots of Figure 8 gave the closest values for single-phase characteristics which to a great extent conform to the simulated result. It can be verified in Figure 17 that the range of the load angles at which the motor can operate with minimal torque pulsation was between $40^{\circ}$ to $50^{\circ}$ (electrical); since in the plot of T3S, the range at the point of operating load angle was the closest range to zero pulsation.

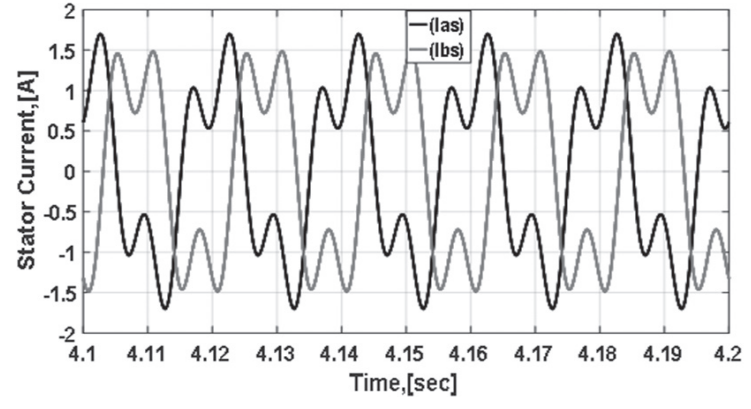

Fig. 8. Current Plots Versus Time

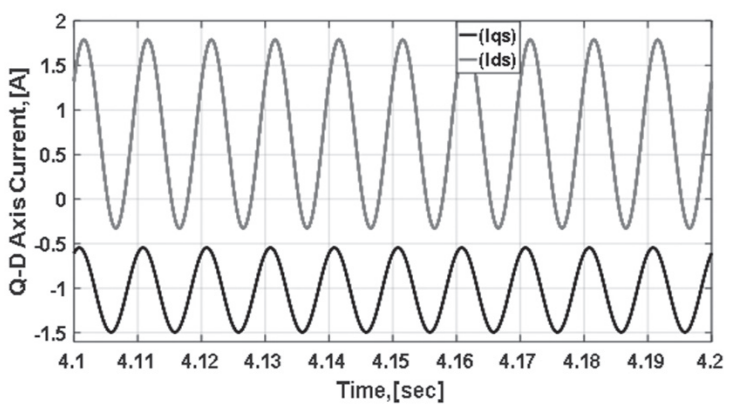

Fig. 9. Stator Current Plots against Time $t$

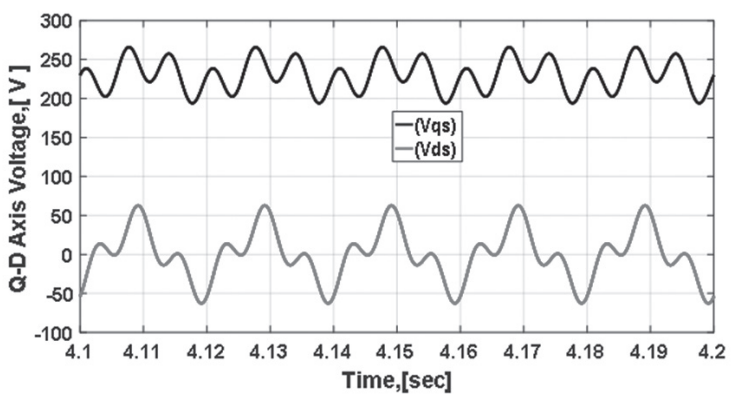

Fig. 10. Capacitor Voltage Plots Versus Time

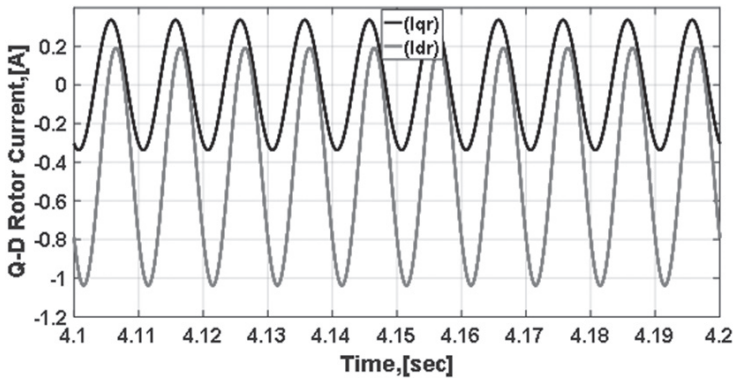

Fig. 11. Rotor Current Plots against Time

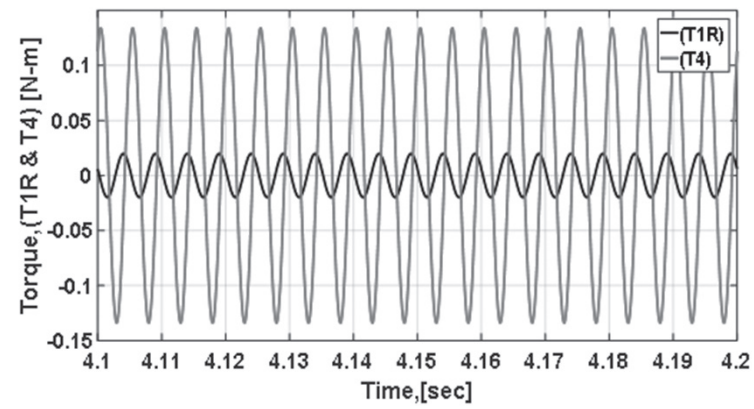

Fig. 12. Pulsating Torque Plots Versus Time 


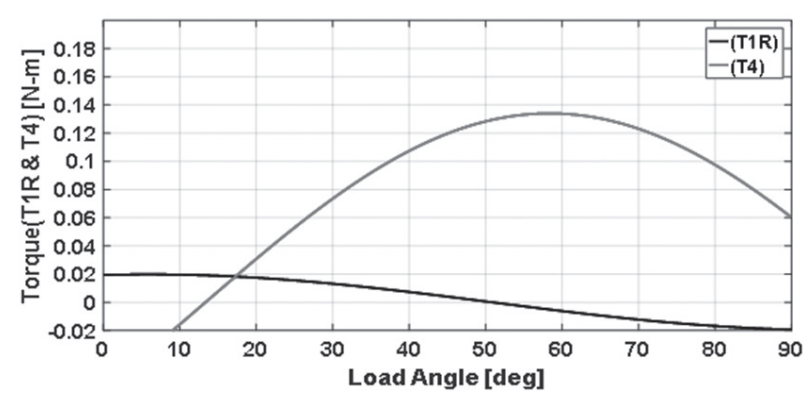

Fig. 13. Pulsating Torques Plots against Load Angle

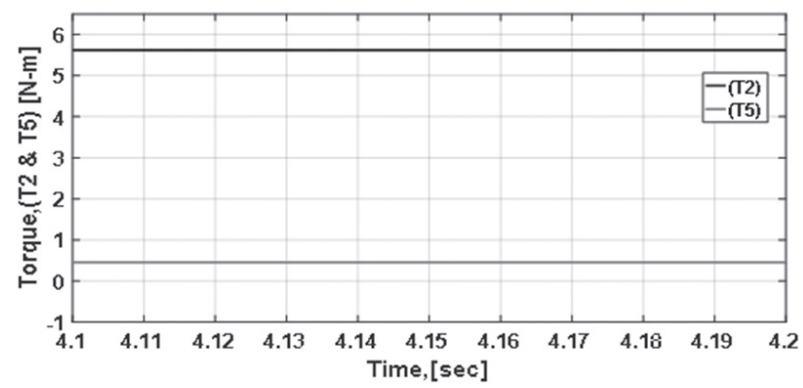

Fig. 14. Average Torque Plots Versus Time

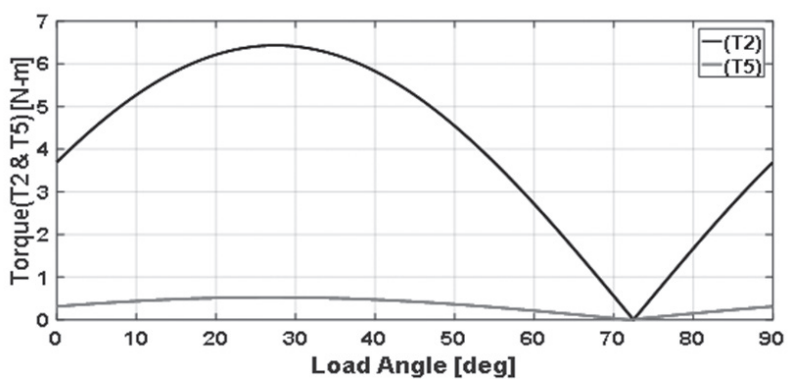

Fig. 15. Average Torques Plots against Load Angle

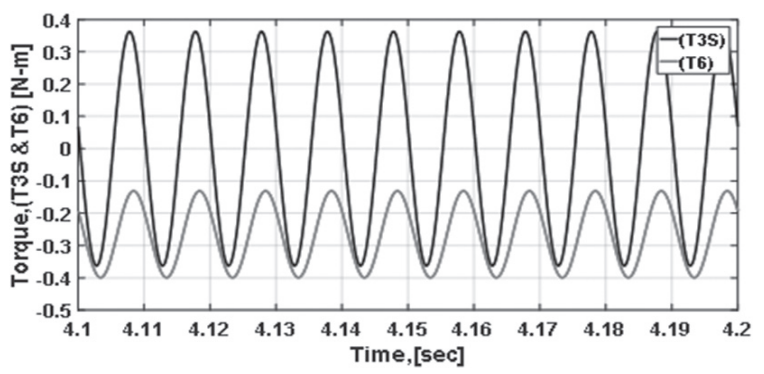

Fig. 16. Pulsating Torque Plots Versus Time

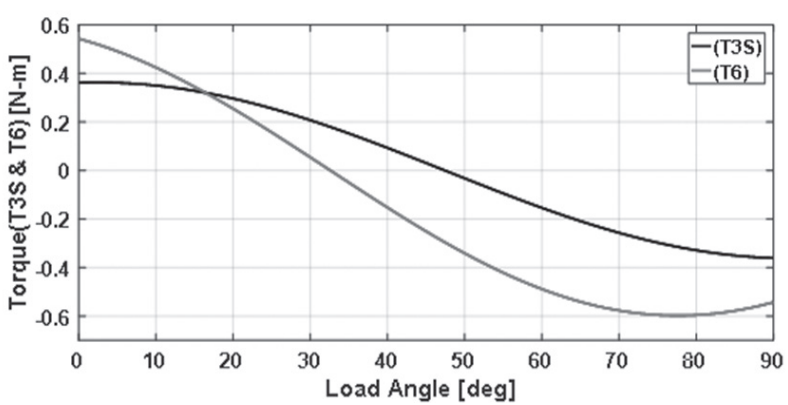

Fig. 17. Pulsating Torques Plots against Load Angle

\subsection{Discussion of Results}

The various capacitor voltages, currents, and torque components and their responses to time and load angles both for the dynamic simulation and the computations are as displayed above in Figures 3 - 17. The motor torques of the computed results ranging from average to pulsating torques were also displayed. There are two number average torque components while the pulsating torques are four in number. The major contributor to torque pulsation is the double frequency component (T3S \& T6) as can be observed. The total indicator runout (TIR) was a pulsating torque component that has a quadruple frequency due to the rotor saliency but oscillating at $\left(\omega_{r}+\omega_{e}\right)$ and $\left(\omega_{r}-\omega_{e}\right)$; this arose as a result of the rotor saliency. It is relying on the weak capacitor value and cannot be curtailed; their minimization hinged on the rotor geometry and was gotten from the ratio of $L_{d} / L_{q}$ of the machine, the higher the ratio the healthier the machine proficiency and power factor. $T_{2}$ was the arithmetic mean of the torque component that was hooked up on both capacitor value and the voltage load angle $(\delta)$. Their dependency on capacitor value is strong. If for any reason the rotor speed swerved from the synchronous speed, then it can dangle at ( $\omega_{r-}$ $\omega_{e}$ ), meanwhile, as $\omega_{e}=\omega_{r}$ (at steady state), it produced an average torque component. Furthermore, $T_{35}$ was a dual-frequency aspect that oscillated at $2 \omega_{e}$ and arose as a result of disparity in the magnetomotive force in the stator rising from main and auxiliary windings. Its reliance on capacitor was too tight hence could be curtailed. $T_{4}$ was the quadruple element established as a result of the collaboration within the onward and regressive components of the permanent magnet flux. The signal was weak and the minimization made an insignificant influence on the entire torque performance. $\mathrm{T}_{5}$ was another average torque that boosted the machine's performance. $T_{6}$ was a twofold frequency constituent that oscillated at $2 \omega_{e}$ and ascended as a result of an imbalance in the rotor permanent magnet flux. It was a negative revolving torque component beyond 330 load angle but from $0^{\circ}$ to $20^{\circ}$, it revolved in the positive direction, unlike other pulsating torque components that were independent of load angle $(\delta)$ of the machine and oscillate in the negative and positive direction at any point in time.

\section{CONCLUSIONS}

Single-phase synchronous motor analysis is not easy to come by owing to its inherent asymmetrical features, but it even becomes much complicated with the introduction of a permanent magnet as an integral part of it, since permanent magnet machine performance indices are characterized by high torque ripples. However, the painstaking efforts put in this novelty work for the IPM machine analysis have successfully paid off. This paper showcased a unified study of high-efficiency single-phase line-start IPM motor that permitted the obtaining of the steady-state, as well as dynamic and 
transient performances analysis of the motor for different functional settings. A mathematical model developed for the motor was based on $\mathrm{d}$-q axis theory and harmonic balance techniques, coupled with the derivation of the inductances as peculiar to the machine. Simulation and computed results of the fractional horsepower having optimum starting and running stator capacitance of $50 \mu F$ and $15 \mu F$ for different operating conditions are presented.

The simulated results to a large extent conform with computed results; the minor variation could be ascribed to the non- enclosure of saturation effect of the third harmonic frequency components inherent in the stator of single-phase machines in the model equation of the dynamic simulation. Most importantly, the work has discovered the average and pulsating torques inherent in IPM machines during its asynchronous and steady-state mode of operations. Those torques as discovered and presented have been categorized and their functional pulsating characteristics fully analyzed. Secondly, it optimized the performance of singlephase IPM machines as the impact of the pulsating torques can be extensively minimized by operating the machine within the range of the load angles at which the motor can operate with minimal torque pulsations [17]; which is between $40^{\circ}$ to $50^{\circ}$ (electrical) since in $\mathrm{T} 3 \mathrm{~S}$, that range at the point of operating load angle of $42^{\circ}$ is the closest range to zero pulsation. At this point, it becomes imperative that a narrow load angle range as this can not be the best expected. Hence, further effort should be made to widen the load angle gap, incorporate electronic circuits for better control, taking their attendant setbacks into consideration.

\section{REFERENCES}

[1]. M. Popescu, T. J. E. Miller, M. I. Mcgilp, G. Strappazzon, N. Trivillin, R. Santarossa, "Line-start permanent-magnet motor: Single-phase starting performance analysis", IEEE Transactions on Industry Applications, Vol. 39, No. 4, 2003, pp. 1021-1030.

[2]. T. J. E. Miller, "Single-phase permanent-magnet motor analysis", IEEE Transactions on Industry Applications Vol. IA-2 1, No. 3, 1985, pp. 651-658.

[3]. O. Ojo, A. Ginart, O. Omozusi, A. A. Jimoh, “Modelling and analysis of a single-phase synchronousreluctance machine including saturation effect", Conference Record of the 1997 IEEE Industry Applications Conference Thirty-Second IAS Annual Meeting, New Orleans, LA, USA, 5-9 October 1997, pp. 290-301.

[4] O. A. Osaloni, "Performance analysis and nonlinear feedback control of interior permanent mag- net synchronous motor", Tennessee Technological University Faculty of the Graduate School, PhD Thesis, 2003.

[5] B. A. Welchko, T. M. Jahns, S. Hiti; "IPM Synchronous Machine Drive Response to a Single-phase Open Circuit Fault", Proceedings of the Applied Power Electronics Conference and Exposition, Anaheim, CA, USA, 4-8 March 2001, pp. 421-427.

[6]. O. Ojo, Z. Wu, "Modeling of the doubly-fed reluctance machines using harmonic balance technique and Manley-Rowe power frequency relationships", Conference Record of the $199631^{\text {st }}$ IAS annual meeting, Vol2, San Diego, CA, USA, 6-10 October 1996, pp. 794-800.

[7]. E. S. Obe, A. Binder, "Calculation of Rotor Currents of Single-phase Synchronous Reluctance Motor Using d-q Harmonic Balance Techniques", Electric Power Components and Systems, Vol. 37, No. 9, 2009, pp. 943-956.

[8] T. J. E. Miller, "Single-phase permanent-magnet motor analysis", IEEE Transactions on Industry Applications, Vol. IA-2 1, No. 3, 1985, pp. 651-658.

[9]. J. W. Finch, P. J. Lawrenson, "Asynchronous performance of single-phase reluctance motors", Proceedings of the Institution of Electrical Engineers, Vol. 126, 1979, pp. 1249-1254.

[10] T. A. Lipo, "Performance Calculations of a Reluctance Motor Drive by DQ Harmonic Balance", IEEE Transactions on Industry Applications, Vol. IA-15, No. 1, 1979, pp. 25-35.

[11]. M. A. Rahman, A. M. Osheiba, K. Kazumi, M. A, Jebbar, H. W. Ping, K. Wang, M. Z. Hossan, "Advances on Single-Phase Line-Start High-Efficiency Interior Permanent Magnet Motors", IEEE Transaction on Industrial Electronics, Vol. 59, No. 3, 2012, pp. 1333-1345.

[12]. J. W. Finch, P. J. Lawrenson, "Synchronous performance of a single-phase reluctance machines", Proceedings of the Institution of Electrical Engineers, Vol. 125, No. 12, 1978, pp. 1350-1356.

[13]. R. Kerkman, "Machine analysis with unbalanced terminal constraints by $\mathrm{d}$-q harmonic balance", IEE Proceedings B (Electric Power Applications), Vol. 128, 1981, pp. 343-357. 
[14]. E. S. Obe, O. Ojo "Line-start performance of singlephase synchronous reluctance motor with a controlled capacitor", IEE Proceedings - Electric Power Applications, Vol. 152, No. 4, 2005, pp. 967-976.

[15]. E. S. Obe, T. Senjyu, M. U. Agu, L. U. Anih, O. Ojo, "Steady-state components in a balanced singlephase synchronous reluctance motor with a running capacitor", Electric Power Systems Research, Vol. 77, No. 3-4, 2007, pp. 295-302.
[16]. M. A. Rahman, A. M. Osheiba, K. Kazumi, M. A, Jebbar, H. W. Ping, K. Wang, M. Z. Hossan, "Advances on Single-Phase Line-Start High-Efficiency Interior Permanent Magnet Motors", IEEE Transaction on Industrial Electronics, Vol. 59, No. 3, 2012, pp. 1333-1345.

[17]. M. J. Thomas, W. L. Soong, “Pulsating Torque Minimization Techniques for Permanent Magnet AC Motor Drives-A Review", IEEE transactions on industrial electronics, Vol. 43, No. 2, 1996, pp. 321-329. 